\title{
Obstacles in employing evidence-based practice by nurses in their clinical settings: a descriptive study
}

Original article

Manal Hamed Mahmouda,*, Zizi Fikry Mohamed Abdelrasol ${ }^{\mathrm{b}}$

aMedical-Surgical Nursing, Faculty of Nursing, Benha University, Kalubia 13741, Egypt

${ }^{b}$ Medical-Surgical Nursing, Faculty of Nursing, Damanhour University, Damanhour, Egypt

Received: 12 September 2018; Accepted: 7 December 2018; Published: 20 June 2019

Abstract: Objective: The challenge of employing evidence-based practice (EBP) is multifarious and varied. Nursing interventions supported by research evidence have been exposed to progress positive patient outcomes, while its implementation is faced with various obstacles. This study aimed to identify obstacles in employing EBP by nurses in their clinical settings.

Methods: This descriptive design study was conducted at Benha University Hospital with a convenient sample of 154 nurses. Two tools were utilized: (I) sociodemographic data sheet, which included sociodemographic characteristics of the participants, and (II) interview scale, which contained two parts: (1) obstacles scale, which contained obstacles that impede nurses from the utilization of EBP, and (2) questions to rank the three greatest obstacles in employing EBP by nurses.

Results: The greatest EBP obstacle ranked by nurses was the organizational limitations $(90.9 \%)$, followed by research quality $(86.9 \%)$ and research accessibility (51.0\%), while individual characteristics (35.9\%) were ranked as the least obstacle. There was a significant statistical correlation between organizational limitations, research quality as well accessibility-related obstacles and nurses' age, level of education, as well their years of work experience $(P<0.05)$.

Conclusions: Findings of this study showed series of obstacles in employing EBP by nurses in their clinical settings, stressing the call for expansion of nurses' capabilities related to EBP utilization in patients' care.

Keywords: evidence-based practice $\bullet$ clinical settings $\bullet$ obstacles

(c) Shanxi Medical Periodical Press.

\section{Introduction}

Nurses undertake a vital responsibility in caring for hospitalized patients, as this obedience expends nearly all time in direct patient care. Findings from numerous studies suggest that $30 \%$ to $40 \%$ of patients do not obtain care per evidence. ${ }^{1}$ Nowadays, nursing practice requires the utilization of information on executive skills to offer best practice and high-quality patient care outcomes. ${ }^{2}$
Nurses reported the least applications of evidencebased practices (EBPs). Enhancing nursing knowledge of and devotion to EBPs is one of the initial steps to fill the nursing research-practice gap. Enhanced patient health and decreased healthcare expenses can eventually be achieved by minimizing nursing practice divergence through the victorious performance of EBP. ${ }^{3}$

Globally, EBP has been the main concern for several years. Health and social services should be supported

How to cite this article: Mahmoud MH, Abdelrasol ZFM. Obstacles in employing evidence-based practice by nurses in their clinical settings: a descriptive study. Front Nurs. 2019; 2: xx-xx. 
by the novel research evidence. ${ }^{4}$ EBP is defined as the structured utilization of the obtainable best accessible evidence in creating clinical decisions pertaining to patient care. ${ }^{5}$ EBP is not merely clinical problemsolving, but it is a method for resolving clinical problems and constructing decisions about implementation. EBP is an organized process of appraising the best accessible research evidence and then integrating clinical experience and patient preferences into the merge. ${ }^{6}$

Evidence-based nursing practice is a process created by the gathering, interpretation, and incorporation of legitimate, significant, and applicable research. The purpose of EBP is to use the data produced by scientific research in clinical practice. ${ }^{7}$ Furthermore, utilizing research evidence to daily clinical practice not only may improve the quality of nursing care but also can lead to developing nurses' individual and professional performance. $^{8}$

Employing research findings at the top of care delivery is vital to developing healthcare processes and patient outcomes. As nursing science has grown in depth and breadth, we currently have evidence to conduct our practice in a number of areas such as pain management, transitional care, pressure ulcer prevention, and others. ${ }^{9}$ The changeover from depending on "expert" view to research-bear facts is necessary to maintain the ongoing revolution of nursing as a scientific discipline. ${ }^{10}$

Prior studies have noted that both individual and organizational factors are associated with obstacles to utilization of EBP, including inadequate time to read literature, intense workload, shortage of staff qualified in EBP, and deficiency of resources. ${ }^{11,12}$ A recent systematic review reported that there were several obstacles to the execution and application of EBP and noted that identifying obstacles was the initial step to eradicating them. ${ }^{13}$ Consequently, understanding the obstacles between research outcomes and their applications in hospitals will encourage the use of EBP. Furthermore, integrating the EBP philosophy inside the field of nursing care practice will progress the value of nursing care and improve the level of patients' satisfaction. ${ }^{14}$

\subsection{Significance of the study}

EBP is a central element of quality patient care, lessening practice dissimilarity and improving nursing selfgovernance. ${ }^{15}$ It also enhances healthcare value and cultivates nurses' dynamic commitment to their practices. Nurses who utilize an EBP, advance to care and practice in the environment that encourages EBP are more authorized as they are capable of creating diversity in the care of their patients. ${ }^{16}$ In addition, utilization of EBP is reflected on the finest technique for developing nurses' talent to discover and solve clinical problems. This implies that nurses have developed the skills and knowledge to search for, appraise and employ research evidence for clinical decision construction and to help techniques to convey high-quality care. ${ }^{17}$

While the optimistic force of EBP has been established throughout various studies, foremost obstacles subsist that hinder EBP from becoming the standard of care all over the world. These obstacles include insufficient EBP knowledge and skills of nurses, misperceptions that EBP needs excessive time, organizational culture and policies, as well as inadequate support from nurse leaders and managers, in addition to lack of resources and investment in EBP. The level to which nurses implicated in EBP and were able to utilize it in the study's hospital was unidentified. ${ }^{18}$ Therefore, the purpose of this study was to identify obstacles in employing EBP by nurses in their clinical settings.

\subsection{Aim of the study}

This study aimed to identify the obstacles in employing EBP by nurses in their clinical settings.

\subsection{Research questions}

(1) What are obstacles in employing EBP by nurses in their clinical settings?

(2) What are the ranks of the greatest obstacles in employing EBP by the studied nurses?

\section{Subjects and methods}

\subsection{Subjects}

This descriptive design utilized to conduct the current study was carried out at Benha University Hospital in medical and surgical units as well as outpatient clinics located at Benha City, Al Qalyubia Governorate. A convenient sample of 154 nurses working at Benha University Hospital in medical and surgical departments, operating theatre, critical care units, and outpatient clinics were willing to participate in the study.

\subsection{Tools}

Two tools were utilized to carry out this study.

\subsubsection{Tool I: sociodemographic data sheet}

It included the sociodemographic data of the study participants such as age, sex, level of education, years of experience and departments. 


\subsubsection{Tool II: obstacles questionnaire}

It contained two parts. Part (1) consisted of obstacles to EBP scale, which were adapted from Funk et al. ${ }^{19}$ It is a Likert-type scale with five options: strongly agree, agree, unsure, disagree, and strongly disagree. It contained obstacles that impede nurses from the utilization of EBP in the patient care. The scale was divided into four parts: the first part included nine obstacles related to individual characteristics, the second part contained nine obstacles allied to organization limitations, the third part consisted of seven obstacles linked to research qualities, and the fourth part comprised five obstacles joined to research accessibility.

Part 2 involved questions to rank the three greatest obstacles in employing EBP by nurses.

\subsubsection{Validity and reliability}

The developed instrument tested for its content validity through five experts from the medical-surgical nursing department. Reliability of tool II was tested through a pilot study by using Cronbach's alpha test. Its value was 0.79 , which reflects that the obstacles scale was highly reliable.

\subsection{Ethical considerations}

An official permission was obtained from hospital medical directors of Benha University Hospital and nursing directors to accomplish the current study. Then, the study's possible participants congregated and a clarification of the study nature, purpose, and procedure were provided to them. They informed that participation is voluntary, that their responses will be confidential and that any information gained from their responses will be presented in a cumulative format and nothing will be exposed to their personal identity.

\subsection{Fieldwork}

The fieldwork of this research occurred on November 2017 until February 2018. An oral consent was obtained from nurses to participate in the current study, and they provided with an explanation about the aim of the study before participation. After that, the study tools were handed to them to fill.

\subsection{The pilot study}

A pilot study was accomplished in $10 \%$ of the study sample to test the clarity and validity of the study tool contents, and subjects involved in the pilot study were excluded from the study sample.

\subsection{Statistical analysis}

The calculated data were analyzed and tabulated using number and percentage distribution for qualitative data and mean and standard deviation for quantitative data, and correlation coefficient $(r)$ was calculated using SPSS, version 20 , to determine if there were statistically significant relations.

\section{Results}

Table 1 shows the distribution of study sample regarding sociodemographic characteristics. It was observed that high percentages of studied subjects were females $(93.5 \%)$ and about half of them were in the age group of 35-45 years and had 10-15 years of work experience (51\% \& 51.6\%) respectively. Additionally, most of them $(64.7 \%)$ had a diploma degree, and more than one-third of them were working in the outpatient clinics.

Table 2 reveals that the majority of the studied subjects $(88.8 \%, 87.1 \%$, and $83.6 \%$, respectively) agreed and strongly agreed with unwilling to try a new idea, low benefits from changing practice, and research were

\begin{tabular}{|c|c|c|}
\hline Sociodemographic characteristics & $n$ & $\%$ \\
\hline \multicolumn{3}{|l|}{ Sex } \\
\hline Male & 10 & 6.5 \\
\hline Female & 143 & 93.5 \\
\hline \multicolumn{3}{|l|}{ Age (years) } \\
\hline$<35$ & 54 & 35.4 \\
\hline $35-<45$ & 78 & 51 \\
\hline$\geq 45$ & 21 & 13.6 \\
\hline $\mathrm{M} \pm \mathrm{SD}$ & $39.9 \pm 13.9$ & \\
\hline \multicolumn{3}{|l|}{ Level of education } \\
\hline Secondary schools & 99 & 64.7 \\
\hline Technical Institute & 32 & 20.8 \\
\hline Bachelor degree & 13 & 8.5 \\
\hline Postgraduation degree & 9 & 5.9 \\
\hline \multicolumn{3}{|l|}{ Years of work experience } \\
\hline$<10$ & 50 & 32.7 \\
\hline $10-<15$ & 79 & 51.6 \\
\hline$\geq 15$ & 24 & 15.6 \\
\hline $\mathrm{M} \pm \mathrm{SD}$ & $13.9 \pm 8.5$ & \\
\hline \multicolumn{3}{|l|}{ Clinical department } \\
\hline Medical department & 32 & 20.8 \\
\hline Surgical department & 24 & 15.6 \\
\hline Critical care units & 26 & 16.9 \\
\hline Operating theater & 21 & 13.6 \\
\hline Outpatient clinics & 51 & 33.1 \\
\hline
\end{tabular}

Table 1. Frequency distribution of studied nurses regarding sociodemographic characteristics $(N=154)$. 
not valuable for practice. Furthermore, $81.6 \%$ of them agreed that they were unable to evaluate research quality, while nearly half of them disagreed or strongly disagreed that they had distrust from the research results (46.4\%).

Table 3 presents that the majority of the studied nurses $(90.2 \%, 86.2 \%$, and $84.9 \%$, respectively) agreed and strongly agreed that the inadequate facilities, lack of authority to change care, and absence of library at the hospital are the highest organizational limitation obstacles. Moreover $(83.6 \%, 83 \%$, and $80.4 \%$, respectively) agree and strongly agree that there is no support from other staff, research results are not universal to own setting, and there is a lack of time to read the research.

Regarding research quality obstacles, most of the studied nurses $(90.1 \%, 86.9 \%$, and $79.8 \%)$ consequently rank, agree, and strongly agree that publishing takes a long time, language of published researches, and conclusions are not reasonable are main obstacles for EBP, as represented in Table 4.

As regard to research accessibility, Table 5 illustrates that most of the studied nurses $(86.9 \%, 84.9 \%$, and $82.4 \%$ ) rank, agree, and strongly agree that the vagueness of research implication for practice absence of research articles clarity and irrelevance of researches to practice are the most perceived obstacles to them.

Table 6 and Figure 1 represent ranking of obstacles to EBP utilization and percentages of studied subjects who perceive barriers as a high and moderate barrier. The table shows that organizational limitations are the greatest obstacle $(90.9 \%)$, followed by the research quality of the research obstacle $(86.9 \%)$, accessibility of the research obstacle $(51.0 \%)$ and the individual obstacle $(35.9 \%)$.

Table 7 reveals that there is a significant correlation between nurses' age and EBP obstacles such as individual characteristics, research quality, and research accessibility ( $P<0.03, P<0.03$, and $P<0.04$, respectively) as well as level of education and the same obstacles $(P<0.01, \quad P<0.001$, and $P<0.002$, respectively) and there is a significant correlation between their sex and research accessibility only $(P<0.03)$. Moreover, their experience is highly correlated with individual characteristics, research quality, and accessibility obstacles $(P<0.000, P<0.008$, and $P<0.001$ respectively $)$, while

\begin{tabular}{|c|c|c|c|c|c|c|c|c|c|c|c|}
\hline \multirow[t]{2}{*}{ Obstacle } & \multirow[t]{2}{*}{ Rank } & \multicolumn{2}{|c|}{$\begin{array}{l}\text { Strongly } \\
\text { disagree }\end{array}$} & \multicolumn{2}{|c|}{ Disagree } & \multicolumn{2}{|c|}{ Unsure } & \multicolumn{2}{|c|}{ Strongly agree } & \multicolumn{2}{|c|}{ Agree } \\
\hline & & $n$ & $\%$ & $n$ & $\%$ & $n$ & $\%$ & $n$ & $\%$ & $n$ & $\%$ \\
\hline Unwilling to try new ideas & 1 & 2 & 1.4 & 5 & 3.3 & 10 & 6.5 & 53 & 34.6 & 83 & 54.2 \\
\hline Low benefits from changing practice & 2 & 2 & 1.3 & 8 & 5.2 & 10 & 7.4 & 77 & 50.4 & 56 & 36.7 \\
\hline Research is not valuable for practice & 3 & 3 & 2.0 & 8 & 5.2 & 15 & 9.8 & 60 & 39.2 & 68 & 44.4 \\
\hline Inability to evaluate research quality & 4 & 7 & 4.5 & 11 & 7.2 & 10 & 6.5 & 66 & 43.1 & 59 & 38.5 \\
\hline Little benefit for self & 5 & 9 & 5.9 & 14 & 9.1 & 9 & 5.9 & 71 & 46.4 & 50 & 32.6 \\
\hline There is no need to change practice & 6 & 5 & 3.3 & 11 & 7.2 & 18 & 11.8 & 72 & 47.1 & 47 & 30.7 \\
\hline Lack of awareness about the research & 7 & 25 & 16.3 & 13 & 8.5 & 16 & 10.5 & 65 & 42.5 & 34 & 22.2 \\
\hline No contact with colleagues & 8 & 15 & 9.8 & 37 & 24.2 & 17 & 11.1 & 62 & 40.5 & 22 & 14.4 \\
\hline Distrust from the research results & 9 & 26 & 16.9 & 45 & 29.5 & 17 & 11.2 & 50 & 32.6 & 15 & 9.8 \\
\hline
\end{tabular}

Table 2. Distribution of study sample regarding individual characteristics $(N=154)$.

\begin{tabular}{|c|c|c|c|c|c|c|c|c|c|c|c|}
\hline \multirow[t]{2}{*}{ Obstacle } & \multirow[t]{2}{*}{ Rank } & \multicolumn{2}{|c|}{ Strongly disagree } & \multicolumn{2}{|c|}{ Disagree } & \multicolumn{2}{|c|}{ Unsure } & \multicolumn{2}{|c|}{ Strongly agree } & \multicolumn{2}{|c|}{ Agree } \\
\hline & & $n$ & $\%$ & $n$ & $\%$ & $n$ & $\%$ & $n$ & $\%$ & $n$ & $\%$ \\
\hline Inadequate facilities & 1 & 4 & 2.6 & 8 & 5.2 & 3 & 2.0 & 80 & 52.3 & 58 & 37.9 \\
\hline Lack of authority to change care & 2 & 7 & 4.6 & 4 & 2.6 & 10 & 6.5 & 67 & 43.7 & 65 & 42.5 \\
\hline There is no library at the hospital & 3 & 7 & 4.6 & 12 & 7.8 & 4 & 2.6 & 83 & 54.2 & 47 & 30.7 \\
\hline Other staff are not supportive & 4 & 9 & 5.9 & 12 & 7.8 & 4 & 2.6 & 62 & 40.5 & 66 & 43.1 \\
\hline Results are not universal to own setting & 6 & 7 & 4.6 & 12 & 7.8 & 7 & 4.6 & 80 & 52.3 & 47 & 30.7 \\
\hline Lack of time to read research & 5 & 9 & 5.9 & 9 & 5.9 & 12 & 7.8 & 57 & 37.3 & 66 & 43.1 \\
\hline Administration hinder achievement & 7 & 4 & 2.6 & 30 & 19.6 & 9 & 5.9 & 72 & 47.1 & 38 & 24.8 \\
\hline Insufficient time to apply a new idea & 8 & 11 & 7.2 & 9 & 5.9 & 35 & 22.9 & 48 & 31.4 & 50 & 32.7 \\
\hline Physicians are not cooperative & 9 & 4 & 2.6 & 47 & 30.7 & 10 & 6.5 & 69 & 45.1 & 23 & 15.0 \\
\hline
\end{tabular}

Table 3. Distribution of study sample regarding organizational limitations $(N=154)$. 


\begin{tabular}{|c|c|c|c|c|c|c|c|c|c|c|c|}
\hline \multirow[t]{2}{*}{ Obstacle } & \multirow[t]{2}{*}{ Rank } & \multicolumn{2}{|c|}{ Strongly disagree } & \multicolumn{2}{|c|}{ Disagree } & \multicolumn{2}{|c|}{ Unsure } & \multicolumn{2}{|c|}{ Strongly agree } & \multicolumn{2}{|c|}{ Agree } \\
\hline & & $n$ & $\%$ & $n$ & $\%$ & $n$ & $\%$ & $n$ & $\%$ & $n$ & $\%$ \\
\hline Publishing takes a long time & 1 & 7 & 4.6 & 4 & 2.6 & 4 & 2.6 & 59 & 38.5 & 79 & 51.6 \\
\hline The language of published researches & 2 & 9 & 5.9 & 7 & 4.6 & 4 & 2.6 & 60 & 39.2 & 73 & 47.7 \\
\hline Conclusions are not reasonable & 3 & 11 & 7.2 & 11 & 7.2 & 9 & 5.9 & 72 & 47.1 & 50 & 32.7 \\
\hline Literature has conflicting results & 4 & 15 & 9.8 & 4 & 2.6 & 15 & 9.8 & 59 & 38.6 & 60 & 39.2 \\
\hline Research has not been replicated & 5 & 15 & 9.8 & 11 & 7.2 & 13 & 8.5 & 54 & 35.3 & 60 & 39.2 \\
\hline Methodological inadequacies & 6 & 19 & 12.4 & 22 & 14.4 & 15 & 9.8 & 46 & 30.1 & 51 & 33.3 \\
\hline Research information is vast & 7 & 15 & 9.8 & 24 & 15.7 & 24 & 15.7 & 58 & 37.9 & 32 & 20.9 \\
\hline
\end{tabular}

Table 4. Distribution of study sample regarding research quality $(N=154)$.

\begin{tabular}{|c|c|c|c|c|c|c|c|c|c|c|c|}
\hline \multirow[t]{2}{*}{ Obstacle } & \multirow[t]{2}{*}{ Rank } & \multicolumn{2}{|c|}{ Strongly disagree } & \multicolumn{2}{|c|}{ Disagree } & \multicolumn{2}{|c|}{ Unsure } & \multicolumn{2}{|c|}{ Strongly agree } & \multicolumn{2}{|c|}{ Agree } \\
\hline & & $n$ & $\%$ & $n$ & $\%$ & $n$ & $\%$ & $n$ & $\%$ & $n$ & $\%$ \\
\hline Implication for practice is vague & 1 & 5 & 3.3 & 4 & 2.6 & 11 & 7.2 & 57 & 37.3 & 76 & 49.6 \\
\hline Research articles are not clear & 2 & 11 & 7.2 & 4 & 2.6 & 5 & 3.3 & 79 & 51.6 & 54 & 33.3 \\
\hline Researches are irrelevant to practice & 3 & 7 & 4.5 & 9 & 5.9 & 11 & 7.2 & 81 & 52.9 & 45 & 29.5 \\
\hline Statistical analyses are unclear & 4 & 15 & 9.8 & 18 & 11.8 & 9 & 5.9 & 48 & 31.4 & 63 & 41.1 \\
\hline Research articles are not available & 5 & 17 & 11.1 & 22 & 14.4 & 12 & 7.8 & 61 & 39.9 & 41 & 26.8 \\
\hline
\end{tabular}

Table 5. Distribution of study sample regarding research accessibility $(N=154)$

\begin{tabular}{lcc}
\hline Obstacles & Rank & Percent \\
\hline \hline Obstacle I: Organizational limitations & 1 & 90.9 \\
Obstacle II: Research quality & 2 & 86.9 \\
Obstacle III: Research accessibility & 3 & 51.0 \\
Obstacle IV: Individual characteristics & 4 & 35.9 \\
\hline
\end{tabular}

Table 6. Rank of obstacles and percentages of nurses who perceived them as high and moderate.

their clinical area is significantly correlated with individual characteristics and research quality $(P<0.003$ and $P<0.001$, respectively).

\section{Discussion}

EBP has been endorsed as a method that obtains the highest level of care in patients, ${ }^{20}$ diminishes the cost of healthcare services, ${ }^{21}$ and encourages the individual and professional progress of nurses and other health personnel. ${ }^{22}$ Furthermore, nurses who practice based on the scientific evidence have been capable of making better decisions in care providing. ${ }^{23}$ Additionally, it is recognized that regardless of the great quantity of text and research that has celebrated the various obstacles to a forceful EBP milieu, using the newest evidence to enlighten decision-making is still challenging. Nurses require the talents requested to set research knowledge, critically evaluate or create the literature, and then apply evidence-based adjustments in multifaceted healthcare settings. ${ }^{24}$ Thus, this study was conducted to assess obstacles to research utilization as perceived by nurses in Benha University Hospital.

The findings of the present study showed that the organizational limitations signify as a strapping obstacle to EBP for nurses. Organizational limitations were the highest barrier as reported by $90.9 \%$ of the nurses, followed by the research quality $(86.9 \%)$, research accessibility $(51.0 \%)$, and finally individual characteristics of nurses as shown in Figure 1 and Table 6. This is in alignment with a number of other studies that confirm that the supreme barriers to EBP are organizational obstacles such as insufficient time at work to implement changes in practice and the quality of research obstacles. ${ }^{24-26}$ These results contradict with another study that showed the utmost obstacle is communication, followed by organization, innovation and research. ${ }^{27}$

\subsection{Obstacle of organizational limitations}

Moreover, the obstacle of organizational limitations were deemed as the greatest obstacle in Benha University Hospital. The majority of the study nurses agreed that there are inadequate facilities, which may be because the setting in the current study has restricted economic and human resources. The restraint of the fiscal resources leads to an intricacy in implementing the research EBP findings, which may need additional equipment and supplies and also inadequate organizational infrastructures 


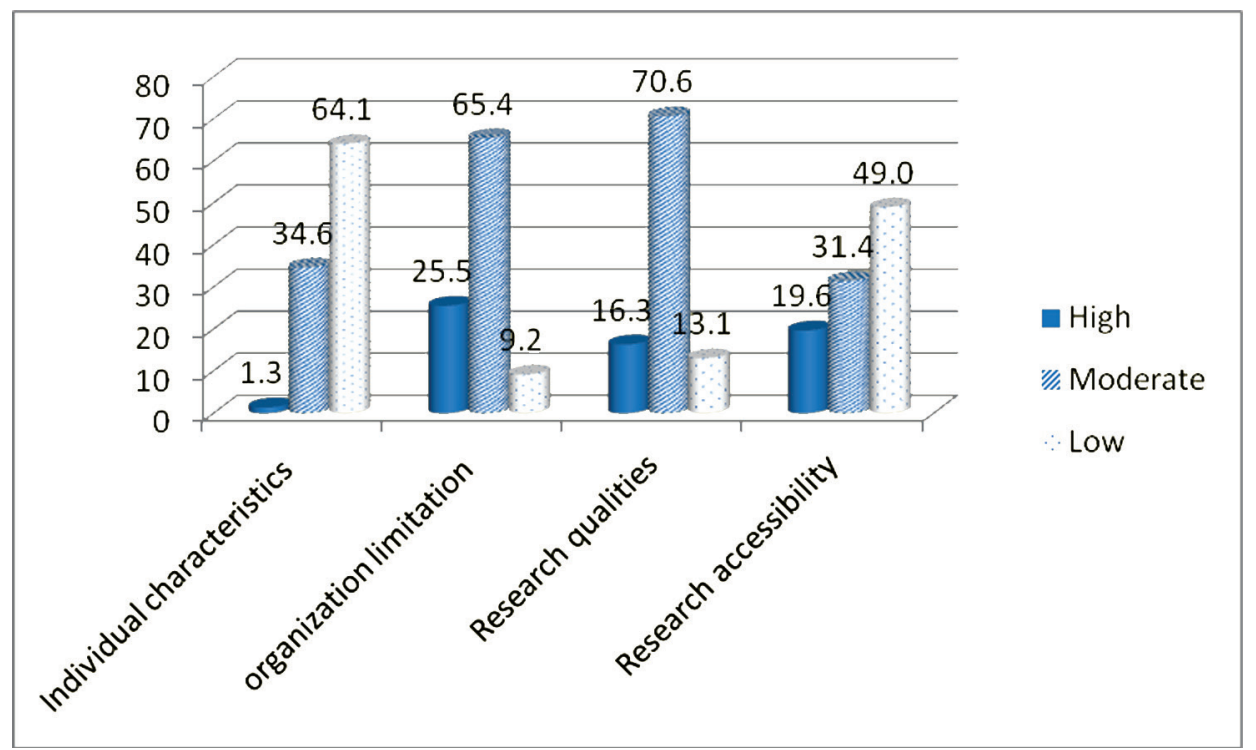

Figure 1. Ranking EBP obstacles as perceived by nurses ( $N=154)$.

\begin{tabular}{|c|c|c|c|c|c|c|c|c|}
\hline \multirow[t]{2}{*}{ Sociodemographic data } & \multicolumn{2}{|c|}{ Individual characteristics } & \multicolumn{2}{|c|}{ Organizational limitations } & \multicolumn{2}{|c|}{ Research quality } & \multicolumn{2}{|c|}{ Research accessibility } \\
\hline & $r$ & $P$ & $r$ & $P$ & $r$ & $P$ & $r$ & $P$ \\
\hline Age & 0.81 & $0.03^{\star}$ & 0.18 & 0.27 & -0.54 & $0.03^{*}$ & -0.57 & $0.04^{\star}$ \\
\hline Sex & 0.13 & 0.09 & 0.23 & 0.67 & 0.42 & 0.060 & 0.29 & $0.03^{*}$ \\
\hline Level of education & 0.52 & $0.01^{*}$ & 0.29 & 1.12 & 0.613 & $0.001^{* *}$ & 0.81 & $0.02^{*}$ \\
\hline Clinic area & 0.23 & $0.003^{*}$ & 0.29 & $0.000^{* *}$ & 0.71 & 0.087 & 0.25 & 0.74 \\
\hline Years of experience & 0.32 & $0.000^{* *}$ & 0.18 & 0.02 & 0.21 & $0.008^{*}$ & -0.74 & $0.001^{* *}$ \\
\hline
\end{tabular}

Note: *Significant $(P<0.05)$;* Significant $(P<0.001)$.

Table 7. Correlation between EBP obstacles and nurses' sociodemographic data $(N=154)$.

that are deliberated to endorse EBP. These findings were consistent with many of previous studies. ${ }^{24,26,28}$ The majority of the studied nurses stated that there is no library in the hospital and they face troubles in attainment of the research evidence. In addition, there is absence of full-text nursing articles or up-to-date textbooks. This is because the restricted Internet access in the hospital does not supply them contact to those databases that contain the massive body of research. Lack of authority to change patient care, which was ranked as the second obstacle for our studied nurses, was inconsistent with previous studies, which ranked it in the top five barriers. ${ }^{29-31}$

Among organization-related obstacles that come at top ranking by the study subjects were the nurses do not have time to read researches, nurses do not feel they have enough authority to change patient care procedures, and the nurses feel results are not generalizable to own setting. These obstacles have often been reported in prior obstacles studies. ${ }^{26,32}$ These results may be attributed to the scarcity of the staff members, intense tasks and workload offered to them, and neither time nor power to read and utilize research findings in their practice. Likewise, a study revealed that head nurses do not have the time to revise research articles, it was rare for head nurses to discuss article findings with nurses, and staff nurses do not have the time to search article reports. ${ }^{33}$ This was supported by another study, which reported that inadequate time and deficiency of EBP education were recognized as the most significant factors hampering applying EBP. ${ }^{34}$ Additionally, other studies reported deficient time to accomplish the entire EBP process as a famous organizational obstacle, while employing EBP is a time-overwhelming process principally concerned with contacting, finding, comprehending, and evaluating research findings as well applying reasonable changes as explained by other studies. ${ }^{35,36}$ This finding is in line with another study, which justified 
that this result may be related to grave workloads and shortage in staffing that hinder the application of EBP. In addition, the subjects in his study viewed nursing care as task orientated. Moreover, nurses in this study supposed that they did not have the authority to implement EBP. Nurses reported that physician's orders were not consistent with nursing research-directed clinical practice. $^{37}$

The findings of the current study showed that another identified organizational obstacle is inadequate support from administration and other staff. From the researchers' view, utilizing research findings in clinical settings needs association among managers, academics, and practitioners. This was consistent with previous studies that noted the same results and found that lack of authority and management support was perceived to resist in opposition to changing the usual practice in the favor of EBP. ${ }^{25,38.39}$

\subsection{Research quality}

Regarding the quality of research-related obstacles, nurses agreed that the publishing takes a long time, the language of the research, the research conclusions are not reasonable, and the research has conflicting results are the greatest obstacles. This may be due to deficiency in efficient communication between researchers and nursing practitioners as a result of disparate beliefs and education and lack of experience, awareness, skills, and motivation in use of research. Another study confirmed that bachelor degree nurses do not learn research-related courses after their graduation, excluding those who schedule postgraduate studies. Deficiency in research-related knowledge makes nurses unable to comprehend methodology and findings of the researches, even if these researches are written in an excellent eminence. ${ }^{40}$

The results of our study showed that the use of English as a dominant language of journals was another apparent obstacle for the nurses, which is concordant with the results of similar studies in other non-English language countries. This is supported by studies conducted in Taiwan presenting that nurses favored evidence-based resources to be obtainable in Chinese. ${ }^{3,40}$ For the most part of the high-quality nursing, studies have been published in English language journals, while most of the Egyptian nurses' proficiency in the English language is comparatively low. This fact highlights the considerable need for support of nurses to develop their English language skills. ${ }^{32}$ Additionally, the absence of translated researches from English to Arabic is considered as the main obstacle to research implementation as most nurses in this study affirmed. This is in line with other studies, which stated that nurses'
English language skills are almost low and the majority of high-quality nurses studies are published in English language. ${ }^{40-42}$

Literature with conflicting results was presented in the top five obstacles that allied with the quality of research. This may be attributed to lack of nurses' fluency with research methodology, as well as the fact that great number of doctors and nurses do not think that research is a nursing duty, which has directed to poor collaboration between doctors and nurses to apply research findings into practice. ${ }^{33}$ Unfortunately, the largest part of the nursing research was conducted by the academic staff at the nursing faculties, and the contact between these researchers and the nursing practitioners is missing. This deficiency in valuable communication may occur because there have different beliefs and levels of education and they do not see each other or speak the same language. ${ }^{43}$ These results are confirmed by another study which reported that nurses in their study had a trouble in appraising the quality of research. So, the research may be complex to be implicated by nurses, or the study results may not congregate the actual requirements of the clinical practice. ${ }^{44}$

\subsection{Research accessibility}

The accessibility of the research was ranked by the study subjects as the third greatest barrier. The nurses agreed that the implications of EBP are vague and not clear, researches are irrelevant to practice, and difficulty in understanding statistical analysis were the main obstacles for research accessibility. This may be due to nurses' inadequate knowledge and training in research methods find it complex to appraise scientific articles and nurses do not have the institution to use the library services. These results are confirmed by previous studies that identified that undependable basic knowledge and familiarity with research have been the main obstacles for utilization of EBP. ${ }^{27,45}$ In addition, previous studies noticed insufficient comprehending of expressions used in research articles as one of the top barriers to EBP. ${ }^{36,46}$ Additionally, another study recognized that nurses deemed insufficient authority and the inaccessibility of research findings to be major barriers to implementing research reports in practice. ${ }^{37}$ Furthermore, a study for evaluation of barriers to the implementation of EBP among nurses working at federal teaching hospital Abakaliki reported understandability of research findings as a main identified barrier by respondents. ${ }^{36}$ However, in contrast, another one that studied 'Nurses' wishes, knowledge, attitudes and perceived barriers on implementing research findings into practice among graduate nurses in Austria" found that more than half percent of the study subjects believed nursing research 
and research used as valuable portions in nursing care, helpful to nurses, and not only pertinent to the actual day-to-day work but also significant to nursing education. ${ }^{47}$

\subsection{Individual characteristics}

The lowest obstacle ranked by nurses in this study was the individual characteristics. The majority of subjects agreed that most individual obstacles in EBP utilization were unwilling to try new ideas, low benefits from changing practice, and research is not valuable for practice. These findings are in agreement with those of other several previous studies that concluded that a lack of assurance in recovering and estimating nursing practice evidence was an extraordinary barrier to approving EBP in none English-speaking countries. ${ }^{17,25,48}$ In addition, the findings of this study are in line with previous studies. ${ }^{26,49}$ These results may be due to nurses with a Master or Ph.D. are not being sufficiently implicated in practical areas, but they speedily look for growing to be faculty staff in various universities or travel for higher income. This will guide to enlarge the gap between theory and practice; they do not profit their hospitals from evidence-based research findings as well as non-existence for role models to other nurses. This was supported by another study that reported that most of the nurses in the developing countries after obtaining a Master or Ph.D. favor going abroad to other countries for enhanced pecuniary and job odds. ${ }^{24}$ On the other hand, one study found that the great bulk of barriers to implementation of EBP are related to individual aspects. ${ }^{50}$ While another one identified cognitive maturity as one of the most important individual factors affecting participation in EBP. ${ }^{51}$

Findings of the present study revealed that most nurses consider themselves unable to evaluate the quality of the research and unable to see the value of the research. This result may be due to a deficiency in nurses' education, training, and participation in research activities, as well as incapability of ongoing education in the hospital to carry out its role in educating and training nurses about the research and evidence-based nursing practice. When nurses comprehend nursing research, this will permit them to enhance research utilization. These findings are in line with previous studies that found that there is a lack of knowledge and skills related to research utilization and EBP. ${ }^{32,52}$ So, the problem of using research findings in nursing is generally described as why nurses in the clinical setting do not adapt their practice in reply to the new data that have been created from nursing research findings. ${ }^{53}$

The sociodemographic variables such as age, educational level, and years of experience were found to be significantly associated with obstacles to implementation of EBP. According to the results of the current study, there is a statistically significant correlation between nurses' age and the obstacles related to individual characteristics, research quality, and accessibility of research. This may be because younger nurses are more overloaded with many job tasks than older. These results are in alignment with the findings of another study..$^{40}$ On the other hand, these findings are inconsistent with the results of a previous study that revealed that there was no relationship between the nurses' age and EBP. 54

In relation to the level of education, the present study reveals that there are statistically significant correlations between educational level and individual characteristics, research quality, and accessibility-related obstacles to EBP. This may be justified as nurses graduated from nursing schools and nursing institutes that signified that the vast number of the study subjects have lack of knowledge and skills about scientific research, how to contact research sources, and research appraisal. In addition, the hospitals do not provide researchassociated education for these nurses. These results are confirmed by a recent study that stated that educational level was extensively linked with organizational barriers to the execution of EBP. ${ }^{50}$ Furthermore, another one noted a statistically significant relationship between nurses' obstacles in the implementation of EBP and educational level. ${ }^{46}$ Contrary to the findings, two studies showed that there is no significant relationship between professional qualification of nurses and exploitation of evidence-based nursing practice. ${ }^{17,36}$

Regarding the nurses' experience, the present study reveals that there is a statistically significant correlation between nurses' experience and obstacles to EBP, except for the organizational limitation-related obstacles. These results may be rationalized as nurses who have adequate experience have superior obstacles to EBP than others. This may be reasonable as a great bulk of the study subjects are young-aged nurses. They may be challenged with many clinical inquiry and questions that need answers from research articles. Accordingly, they may be faced with further research allied obstacles than older nurses. This result is sustained by another one carried out on the individual determinants of nursing research utilization that revealed that current roles, experience working in a specialty area, and job satisfaction were all significant individual characteristics that endorsed nursing research implementation. ${ }^{55}$ In addition, one study showed significant differences in greater utilization intent for EBP according to nurses' professional position in the hospital. ${ }^{56}$ Additionally, another one noted that there was a significant association between job experience and organizational barriers of EBP 
execution. ${ }^{50}$ While, a recent study found a highly statistical significant relationship between nurses' obstacles toward EBP and years of experience. ${ }^{44}$

\section{Conclusions}

The findings from this study confirm that there are a variety of obstacles in EBP implementation by nurses in their clinical settings. However, the findings from this study also indicated that the majority of the nurses are not familiar with EBP, highlighting the need for professional nursing development in our country. The respondents ranked organizational obstacles as the greatest barriers, followed by qualities of the research, accessibility of the research, and individual-related obstacles.

\section{Recommendations}

Based on the findings of the present study, the following recommendations are suggested:

(1) Develop centers in hospitals to evaluate nursing research for its usage in the clinical practice, as

\section{References}

1. Grol R, Wensing M. Effective implementation of change in healthcare: a systematic approach. In Grol R, Wensing M, Davis D. (Eds.), Improving Patient Care: The Implementation of Change in Healthcare (2nd ed.). Oxford, UK: John Wiley \& Sons; 2013: 40-63.

2. Rhodes M, Morris A, Lazenby R. "Nursing at its Best: Competent and Caring". OJIN: The Online Journal of Issues in Nursing; 2011: 16.

3. Weng TH, Kuo KN, Yang CY, Lo HL, Chen C, Chiu TW. Implementation of evidence-based practice across medical, nursing, pharmacological and allied healthcare professionals: a questionnaire survey in nationwide hospital settings. Implement Sci. 2013;8:1-10.

4. World Health Organisation. European Observatory on Health Systems and Policies. Health Evidence Network; 2011. http://www.who.int/evidence/en/.

5. Boyd M. Psychiatric nursing: Contemporary practice (5th ed.). Philadelphia, PA: Lippincott; 2012.

6. Houser J, Oman KS. Evidence based practice. An implementation guide for health care organizations. Kevin Sullivan, London; 2011:13.

7. Centre for Evidence-Based Practice. University of Toronto Health Network. 2013. http://www. cebin.u.torontocal/syllas/nur/intro/htm. well as provide consultation and support regarding research methods and statistical procedures for nurses.

(2) Enhance work environment through declining workload, augment resources, and administrative support to read researches and attempting to apply novel ideas.

(3) Direct contact between researchers and nursing staff through scientific workshops will promote communication and help researchers to delineate their impending studies based on real finding from clinical areas.

(4) Further research should be carried out to evaluate the ability of clinical nurses to apply EBP in their actual practical area.

(5) Supply hospitals with libraries containing valuable and recent researches as well as access to services such as the Internet, which assist nurses to execute EBP.

\section{Conflicts of interest}

All contributing authors declare no conflicts of interest.
8. Chien WT, Bai Q, Wong WK, Wang H, Lu X. Nurses' perceived barriers to and facilitators of research utilization in mainland China: a cross-sectional survey. Open Nurs J. 2013;7:96-106.

9. Avorn J. Transforming trial results into practice change. Arch Int Med; 2010:170:858-560.

10. Ali O, Brand J. Nurses' perceptions of the implementation of evidence-based practice in clinical settings. Thesis dissertation. College of Applied Sciences and Technology; Ball State University; 2013.

11. Solomons NM, Spross JA. Evidence-based practice barriers and facilitators from a continuous quality improvement perspective: an integrative review. $J$ Nurs Manage. 2011; 19:109-120.

12. Varaei S, Salsali M, Cheraghi MA. Implementation of evidence-based nursing practice for diabetic patients: an Iranian experience. Int J Nurs Pract. 2013;19:73-80.

13. Sadeghi-Bazargani H, Tabrizi JS, Azami-Aghdash S. Barriers to evidence-based medicine: a systematic review. J Eval Clin Pract. 2014;20:793-802.

14. Suwanraj M. Current practice perceived barriers, and perceived facilitators of Thai nurses on using evidence-based practice in pain assessment and pain management in older adults. University of lowa. http://ir.uiowa.edu/etd/747. 2010 
15. Bostrom AM, Rudman A, Ehrenberg A, Gustavsson JP, Wallin L. Factors associated with evidencebased practice among registered nurses in Sweden: a national cross-sectional study. BMC Health Serv Res. 2013;13:165.

16. Melnyk BM, Gallagher-Ford L, Thomas BK, Troseth M, Wyngarden K, Szalacha L. A study of chief nurse executives indicates low prioritization of evidence-based practice and shortcomings in hospital performance metrics across the United States. Worldviews Evidence-Based Nurs. 2016; 13:6-14.

17. Hsu LL, Hsieh SI, Huang YH. A study of the evidence-based nursing practice competence of nurses and its clinical applications. Hu Li Za Zhi. 2015;62:30e40 (in Chinese).

18. Jun J, Kovner CT, Stimpfel AW. Barriers and facilitators of nurses' use of clinical practice guidelines: an integrative review. Int J Nurs Stud. 2016;60:54-68.

19. Funk SG, Champagne MT, Wiese RA, Tornquist EM. BARRIERS: The barriers to research utilization scale. Appl Nurs Res. 1991; 4:39-45.

20. Lyons C, Brown T, Tseng MH, Casey J, Mcdonald R. Evidence-based practice and research utilization: perceived research knowledge, attitudes, practices and barriers among Australian paediatric occupational therapists. Aust Occup Ther J. 2011;58:178-186.

21. Fortney JC, Pyne JM, Burgess JF Jr. Populationlevel cost-effectiveness of implementing evidencebased practices into routine care. Health Serv Res. 2014;49:1832-1851

22. Heydari A, Mazlom SR, Ranjbar H, ScurlockEvans L. A study of Iranian nurses' and midwives' knowledge, attitudes, and implementation of evidence-based practice: The time for change has arrived. Worldviews on Evidence-Based Nurs. 2014;11:325-331.

23. Stokke K, Olsen NR, Espehaug B, Nortvedt MW. Evidence based practice beliefs and implementation among nurses: A cross-sectional study. BMC Nurs. 2014;13:8.

24. Hassan S. Barriers to research utilization among nurses practicing at Zagazig University hospitals. Master Degree in Nursing Science; 2011.

25. Wang LP, Jiang $X L$, Wang L, Wang GR, Bai YJ. Barriers to and facilitators of research utilization: a survey of registered nurses in China. PLOS ONE. 2013; 8:e81908

26. Ghulman FA, Salem OA, Baddar FM, Mubaraki BM. Barriers of evidence based practice in Saudi Arabia. IOSR J Nurs Health Sci. 2017;6:10-14.

27. Brown CE, Ecoff L, Kim SC, et al. Multi-institutional study of barriers to research utilization and evidence-based practice among hospital nurses. J Clin Nurs. 2010;19:1944-51.

28. Hassona FM, Winkelman C, El-Sayed SH. The effect of a workshop on Egyptian nurse educators' motivation and attitude toward evidence based teaching. J Nurs Educ Pract. 2013;3:71.

29. El-shaer A, Elhanafy E. Barriers and facilitators to research utilization as perceived by academic staff and head nurses. J Am Sci. 2012;8:406-416.

30. Fathimath Sh, David E, Helen B. Nurses' perceptions of barriers and facilitators to implement EBP in the Maldives. Adv Nurs. 2014;Article ID 698604, 7 pages.

31. Heydari A, Zeydi AE. Barriers to and facilitators of research utilization among Iranian nurses: a literature review. J Caring Sci. 2014;3:265-275.

32. Barnes LM. Evidence based practice in school nursing: a study of school nurses in central and Eastern North Carolina. Gardner-Webb University BMC Health Serv Res. 2012;12:1.

33. Uysal A, Temel AB, Ardahan M, Ozkahraman S. Barriers to research utilization among nurses in Turkey. J Clin Nurs. 2010;19:3443-452.

34. Majid S, Foo S, Luyt B, et al. Adopting evidencebased practice in clinical decision making: nurses' perceptions, knowledge, and barriers. J Med Lib Assoc. 2011;3:229-236.

35. Omer T. Research utilization in a multicultural nursing setting in Saudi Arabia: barriers and facilitators. J Nurs Res. 2012; 20:66-73.

36. Chijindu AV, Samantha ECF, Nkechi EA. Evaluation of barriers to the implementation of evidence-based practice (EBP) among nurses working at federal teaching hospital Abakaliki (FETHA II). Int J Nurs, Midwife Health Relat Cases. 2016;2:71-90.

37. Hadgu G, Almaz S, Tsehay G, Almaz S, Tsehay S. Assessment of nurses' perceptions and barriers on evidence based practice in Tikur Anbessa Specialized Hospital Addis Ababa Ethiopia. Am J Nurs Sci. 2015; 4:73-83.

38. Malik G, McKenna L, Plummer V. Perceived knowledge, skills, attitude and contextual factors affecting evidence-based practice among nurse educators, clinical coaches and nurse specialists. Int J Nurs Pract. 2015;21:46-57.

39. Oluwatoyin FE, EkeFJH, Bisola FB. Knowledge and utilization of evidence-based nursing practice among nurses of Offa Specialist Hospital, Kwara State. IOSR J Nurs Health Sci. 2016;4:51-62.

40. Ezz A, Mohmed E, Hamdi A. Barriers and facilitators to research utilization in critical care settings. J Am Sci. 2011;7:145-154.

41. Chiu YW, Weng YH, Lo HL, Shih YH, Hsu CC, Kuo $\mathrm{KN}$. Comparison of accessing online databases 
between physicians and nurses in Taiwan. Inform Health Soc Care. 2012;37:230-241.

42. Yadav BL, Fealy GM. Irish psychiatric nurses' selfreported sources of knowledge for practice. J Psychiat Mental Health Nurs. 2012;19:40-46.

43. Yava A, Tosun N, Cicek H, Yavan T, Teraky G, Hatipoglu $\mathrm{S}$. Nurses perceptions of the barriers to and the facilitators of research, utilization in Turkey. Appl Nurs Res. 2009;22:166-175.

44. Mohsen MM, Safaan NA, Okby OM. Nurses' perceptions and barriers for adoption of evidence based practice in primary care: bridging the gap. Am J Nurs Res. 2016;4:25-33.

45. Stichler J, Fields W, Kim S, Brown C. Faculty knowledge, attitudes, and perceived barriers to teaching evidence-based nursing. J Prof Nurs. 2011;27:92-100.

46. Mashiach M. Implementation of evidence-based nursing practice: nurses' personal and professional factors? J Adv Nurs. 2011;67:33-42.

47. Breimaier HE, Halfens RJG, Lohrmann C. Nurses' wishes, knowledge, attitudes and perceived barriers on implementing research findings into practice among graduate nurses in Austria. J Clin Nurs. 2011:20:1744-1756.

48. Dalheim A, Harthug S, Nilsen RM, Nortvedt MW. Factors influencing the development of evidencebased practice among nurses: a self-report survey. BMC Health Serv Res. 2012;12:367.
49. Carroll DL. Barriers and facilitators to the utilization of nursing research. Clin Nurs Spec. 2014;11:207-212.

50. Khammarnia M, Haj Mohammadi M, Amani Z, Rezaeian S, Setoodehzadeh F. Barriers to implementation of evidence based practice in Zahedan Teaching Hospitals, Iran. Nurs Res Pract. 2015;5:3.

51. Nickerson CJ. Cognitive maturity and readiness for evidence-based nursing practice. J Nurs Educ. 2013;52:17-23.

52. Hussein AHM, Hussein G. The attitudes and barriers towards evidence-based practice among nursing educators. J Am Sci. 2013;9:609-618.

53. Walsh in Azuka, Ezinwa in Azuka, Ezinwa B. Barriers to and facilitators of research utilization, as perceived by a group of registered nurses in Sweden Author. 2010. http://hdl.handle.net/10755/ 169464.

54. Eizenberg MM. Implementation of evidence-based nursing practice: nurses' personal and professional factors? J Adv Nurs. 2010;67:33-42.

55. Squires JE, Hutchinson AM, Bostrom AM, O'Rourke HM, Cobban SJ, Estabrooks CA. To what extent do nurses use research in clinical practice? A systematic review. Implement Sci. 2011;6:1-17.

56. Park J, Ahn J, Park M. Factors influencing evidence-based nursing utilization intention in Korean practice nurses. Int J Nurs Pract. 2015;21: 868-875. 